\title{
Knowledge is Not Made for Understanding; It is Made for Cutting ${ }^{1}$
}

\author{
DEBORAH OSBERG, Editor-in-chief \\ University of Exeter (United Kingdom)
}

In the last four issues of Complicity, Bill, Donna and I have focused the content of our editorials on what it means to edit or contribute in other ways to a journal of complexity in a manner that does not contradict the "ethos" of complexity, whatever that is. In this regard we have been discussing the merits of a conversational approach in academic journals, and in particular the role of conversation in "enlarging the space of the possible around what it means to educate and be educated" 2 and in unsettling the power dynamics of the "gatekeeper" role. We have argued that a conversational approach in academic journals enables journal editors and reviewers to (i) move from a "policing" to a "facilitating" mode of "gatekeeping," (the former attempts to keep unauthorized ideas out, the latter invites unauthorized ideas in) and that (ii) this mode of gatekeeping ${ }^{3}$ is crucial for enlarging the space of the possible. ${ }^{4}$

\footnotetext{
${ }^{1}$ Original quote cut from Foucault, 1984a, p. 88, but I cut the idea from Simons \& Olssen, 2010, p. 88.

${ }^{2}$ Quote cut from Davis \& Phelps, 2004, p.4. but the original idea is from Sumara \& Davis, 1997.

3 The mode of gatekeeping in question is described in a previous editorial as being about "facilitating engagement between different forms of knowledge, different meanings, so that something else can take place" (cut from Osberg, Doll \& Trueit, 2008, p. vii, emphasis changed).

${ }^{4}$ Note that "enlarging the space of the possible" is, in this context, understood as "entering the space of the impossible" where "the impossible" is understood as "that which cannot currently be conceived as a possibility" (cut from Osberg, 2009, p. vi).
} 
While the conversational approach in academic journals does challenge the power relations normally associated with academic (and especially scientific) knowledge, I have been concerned that there has been insufficient focus on the status of the knowledge that can be said to contribute to the enlargement the space of the possible. There is a danger, in other words, that we understand the notion of enlarging the space of the possible as some sort of progressive and teleological process. After all, when we speak of enlarging the space of the possible, we are still engaging with the idea that there is some sort of directional change going on which results in knowledge that is more powerful because it has greater (more expansive) capability in a particular context (and irrespective of whether the context is scientific, practical, spiritual, political, or whatever). My point is that there still appears to be some sort of hierarchy of knowledge., some sort of power differential. My question, therefore, is: What, exactly, is the nature of this "hierarchy of knowledge," if it exists? And how does power operate within this hierarchy? In this regard I have found Foucault's work helpful, particularly the statement that I have used as a title for this editorial:

Knowledge is not made for understanding; it is made for cutting. (Foucault, 1984a, p. 88)

I believe this statement can be brought into productive conversation with some ideas from complexity thinking, and in a way that addresses the problem of the status of knowledge (in a hierarchical sense) in the process of "enlarging the space of the possible," and this has implications for this journal. Let me begin with the power relations in knowledge that is "made for understanding."

\section{Knowledge is (Not) Made for Understanding}

When we say we "understand" something, we generally mean we have become certain about something, where previously we may have been uncertain or confused. This kind of certainty is very much caught up with authority. When we are certain about what is going on, and how things work we have (or believe we have) greater authority, greater power to command. Hence there appears to be a clear hierarchy of knowledge: the greater our understanding/certainty, the greater our authority. But it is not so simple. The idea that knowledge is differentially authoritative (having different levels of power to command) has long been problematic. There are many arguments to suggest that the assignation of authority has little to do with the certainty of knowledge, little to do with its "truth" or "universality" or even its "usefulness." It is instead an effect of social processes that build and reflect unequal power relationships (see, e.g., Polanyi, 1946, Quine, 1951, Kuhn, 1962, Lyotard, 1984). Such relationships allow dominant members of society to narrate the world - to say this is how it is; this is how things are, or work, and "do you understand me?" 5 - while others are denied this privilege. Furthermore, these power relationships, nourished by the unequal distribution of authority, operate irrespective of whether we adopt an objectivist or relativist epistemological position. For both positions, it is truth and understanding, or certainty, that warrants authority. For the

5 An idea cut from Smitherman-Pratt (2006). 
objectivist, truth is universal, for the relativist, it is situated/contextual. ${ }^{6}$ This is one reason why objectivist and relativist epistemological positions are polarized, and why Bernstein (1983) suggests it is necessary to move "beyond objectivism and relativism." With Foucault, however, it is possible to approach the hierarchy (or power differential) of knowledge in a rather different way, a way which I believe is not only of considerable interest to complexity thinking, but also has implications for (this journal's approach to) publishing academic work.

\section{Knowledge is Made For Cutting}

In his essay entitled "What is Enlightenment?" Foucault takes up the question of how "the growth of capabilities can be disconnected from the intensification of power relations" (1984b, p. 48). He argues that one way in which this can take place is if the growth of capabilities is somehow disconnected from the notion of teleological progress. What is interesting about this position is that Foucault is not suggesting that we discard the notion of the growth of capabilities (a hierarchy that we cannot do without if we are to stick with the idea that knowledge enlarges the space of the possible). What must be discarded is the notion of teleological progress (which results in the smooth or linear intensification of power).

This is precisely where the logic of complexity, or emergence, makes an appearance. In particular, Prigogine's ontology of irreversible temporality (Prigogine \& Stengers, 1984) is important for it offers a notion of directional movement (change) that is nonlinear and non-teleological (i.e., not smooth at all, in fact decidedly bumpy). At the heart of this ontology is the concept of "undecidability." For Prigogine, undecidability (the freedom that exists at "bifurcation" points in far-from-equilibrium systems) is the condition of possibility of irreversible forward directionality. These points of undecidability are points of disruption, where change can no longer proceed incrementally and smoothly. At these points the system is forced to do something unprecedented (in the history of the system). This introduces a discontinuity; a break or "cut" with the continuity of the past. In this sense the system cuts through or out of its past. It cuts into a new space of "being," demonstrating new capabilities which transcend or surpass past capabilities in a qualitative rather than quantitative sense (i.e., not simply increasing in magnitude along a linear scale). I suppose this could be called a "disruptive ontology" in that the smooth intensification (of power) can only proceed so far without being disrupted. The disruption opens a new unprecedented space of being/capability, and hence introduces an entirely different form or order of power, rather than an intensification (or increase in magnitude) of what was already "there." The disruption of continuity is an expression of the irreversible temporality (directionality) of being.

\footnotetext{
${ }^{6}$ While it may be argued that some relativist positions (e.g., postmodernism) escape this because they adopt a position that is skeptical of all claims to truth/authority, they can do so only by (i) asserting the skeptical position as an authoritative position in its own right, and (ii) acknowledging that it is indeed claims to truth and understanding that give knowledge its power.
} 
From an epistemological and complexity thinking perspective, it can be argued that knowledge that enlarges the space of the possible does not simply (progressively) increase capability, but does so by introducing discontinuity. This understanding of knowledge becomes possible only if undecidability is placed at the very centre of the notion of knowledge generation (see Sandbothe, 2001). Placing undecidability at the centre of knowledge making is the same as endorsing that knowledge from very different perspectives is equally authoritative. This is affirming the relativist position, i.e., that all knowledge is true in relation to the context in which it is produced. But it is also affirming of the objectivist position, i.e., that all knowledge is really true, in an objective or universal sense (all "pockets" of knowledge are equally true).

The upshot of assuming all knowledge is authoritatively equal, and objectively true, (even if such truth can only be relative to context in which it was produced), is that authority becomes undecidable. In such circumstances, it is necessary to engage very closely indeed with all the arguments presented. This is not so that we may decide between them, picking the "best," but in order that we may use them to strike our own unique (unprecedented) way forward. In using knowledge to do something different we cannot avoid cutting it up, for we cannot, and could never, use all of it. ${ }^{7}$ From the bits we use, the bits we have cut and spliced into our own thought, we create (new) meaning. Knowledge is not made for understanding; it is made for cutting. It is made to be cut up and it is made for the act of cutting through into a new space of being.

\section{Complicity/Democracy}

In placing undecidability (rather than certainty), at the centre of knowledge and meaning making, complexity can theorize the concept of knowledge as a dynamic point of articulation between different but authoritatively equal positions ("bodies" of knowledge). With this understanding, it is the impossibility of deciding between alternate positions that enables something else to take place. It is the impossibility of deciding that enables the "knowledge front" (i.e., the notion of knowledge having an irreversible forward directionality) to "break new ground." This "cutting edge," of knowledge is no longer a smooth, linear progression towards truth, understanding and certainty (as the notion of "scientific progress" usually implies) but a process of discontinuity, a process of being disrupted, interrupted, and starting again. It is a process of cutting through assumed continuities, and enabling what we, in this journal, have called "enlarging the space of the possible."

This understanding of knowledge as a form of genesis or irreversible directionality (enlarging the space of the possible) challenges the idea that the hierarchy of knowledge is simply a (linear) hierarchy of authority/truth/certainty. A hierarchy of increasing degrees of truth, increasing degrees of authority, increasing degrees of whatever it is that we start with, on a linear quantitative scale. It is not a hierarchy of magnitude. There is, of course, such a hierarchy of authority (with its own peculiar power dynamics), but

\footnotetext{
7 Jimmy Wales, founder of Wikepedia, stated in 2008 that there were more than $10 \mathrm{~m}$ articles in over 150 languages on Wikipedia. http://www.guardian.co.uk/commentisfree/2008/jun/22/wikipedia.internet
} 
there is another kind of hierarchy too-a hierarchy of qualitative change, transcendence-which greatly complicates the scene and opens the possibility to begin theorizing academic journals in another way, as "knowledge democracies" rather than "knowledge monopolies"8

If knowledge is a point of dynamic articulation between multiple (authoritatively equal) bodies of knowledge that are in a continual process of emergence then it is important not to destroy the possibility of such articulation by hiding the appearance of undecidability by selecting articles that are roughly in agreement with each other. In this issue we have made a point of allowing undecidability to appear by presenting two rather different responses to each of the three research articles we have published. Each triad presents a complex range of ideas, which, taken together cannot be "understood." Understanding is not the point. We invite you, our readers, to cut from these pieces, to cut them up, and splice them back together, differently, with your own thoughts, feelings, motivations, desires, experimenting with the possibility of going beyond the historical conditions that we call "the present." Cutting from these pieces, transcending what they, and we, (re)present, is to be complicit in enlarging the space of the possible.

\section{References}

Bergson, H. (1911). Creative evolution, (Trans. A. Mitchell), New York: Henry Holt and Company.

Bernstein, R (1983). Beyond objectivism and relativism: Science, hermeneutics and praxis. University of Pennsylvania Press.

Biesta, G. (2007). Towards the knowledge democracy? knowledge production and the civic role of the university. Studies in Philosophy and Education 26(5): 467-479.

Davis, B. and Phelps, R. 2004. Complicity: An introduction and a welcome. Complicity: An International Journal of Complexity and Education, 1(1): 1-7.

Foucault, M. (1984a). Nietzsche, genealogy, history (pp. 76-100), in P. Rabinow (Ed.) The Foucault reader. New York: Pantheon.

Foucault, M. (1984b). What is Enlightenment? (pp. 32-50), in P. Rabinow (Ed.) The Foucault reader. New York: Pantheon.

Kuhn, T (1962). The Structure of Scientific Revolutions, Chicago: Univ. of Chicago Press.

Lyotard, J-M. (1984). The postmodern condition. A report on knowledge. Manchester: Manchester University Press.

Osberg, D. \& Biesta, G (2007). Beyond presence. epistemological and pedagogical implications of "strong" emergence. Interchange, 38(1): 31-51.

Osberg, D., Doll, W.E \& Trueit, D (2008) Gatekeepers of a complex field? Complicity. An International Journal of Complexity and Education, 5(1): iii-ix.

Osberg, D. (2009). "Enlarging the Space of the possible" around what it means to educate and be educated. Complicity. An International Journal of Complexity and Education, 6(1): iii-x.

Polanyi, M. (1946). Science, faith and society. London: Oxford University Press.

Prigogine \& Stengers (1984). Order out of chaos. Man's new dialogue with nature. New York: Bantam Books.

Quine, W. V. O. (1951) Two dogmas of empiricism Philosophical Review , 60(1): 20-43.

Sandbothe, M. (2001). The temporalisation of time. Basic tendencies in the modern debate on time in philosophy and science. (Trans. A. Inkpin). New York: Rowman \& Littlefield.

\footnotetext{
${ }^{8}$ The idea of "knowledge democracies" or "knowledge monopolies" is cut from Biesta (2007).
} 
Simons, M \& Olssen, M (2010). The school and learning apparatus (pp. 79-92), in Osberg, D \& Biesta, G (Eds.) Complexity theory and the politics of education. Rotterdam: Sense Publishers.

Smitherman-Pratt (2006) Playing with our understandings. Complicity: An International Journal of Complexity and Education, 3(1): 91-95.

Sumara, D.J. \& Davis, B. 1997. Enlarging the space of the possible: Complexity, complicity, and action research practices. In Action Research as a Living Practice (pp. 299-312), edited by T. Carson and D.J. Sumara, New York: Peter Lang.

(C) Copyright 2008. The author, DEBORAH OSBERG, assigns to the University of Alberta and other educational and non-profit institutions a non-exclusive license to use this document for personal use and in courses of instruction provided that the article is used in full and this copyright statement is reproduced. The author also grants a non-exclusive license to the University of Alberta to publish this document in full on the World Wide Web, and for the document to be published on mirrors on the World Wide Web. Any other usage is prohibited without the express permission of the author. 